\title{
A Comparative Study of Carotid Artery Intima Media Thickness in Hypertensive Smokers and Non-Hypertensive Smokers
}

\author{
Aditya Jain ${ }^{1}$, Ajay Pal Singh ${ }^{2}$ \\ ${ }^{1}$ P.G. Student, ${ }^{2}$ Associate Professor, Department of Medicine, Gajra Raja Medical College, Gwalior (M.P.), India
}

\begin{abstract}
Introduction: Cardiovascular disease is the leading cause of death globally. In 2017-18, Non-communicable diseases led to 38 million (68\%) deaths out of a total of 56 million deaths worldwide. India is currently in the midst of this global Cardiovascular Disease epidemic.
\end{abstract}

Method: Case-control study

Aim of the Study: To compare carotid artery intima-media thickness(cIMT) in Hypertensive smokers and smokers without Hypertension.

Result: Mean value of cIMT of the Case group $(0.970 \mathrm{~mm})$ was significantly higher than that of the Control group $(0.735 \mathrm{~mm})$. Mean cIMT was highest in the study group i.e $1.114 \mathrm{~mm}$ in the population of age above 70 years, similarly Mean cIMT was highest in the control group i.e. $0.821 \mathrm{~mm}$ in the population of age above 60 years.

Conclusion: The present study and its observations makes it imminent that Hypertension affects every cIMT measurement of the study subjects. cIMT measurement has a positive correlation with the increasing age.

Keywords: Hypertension, cIMT, Cardiovascular disease

\section{Introduction}

The world's major disease burden is contributed by noncommunicable diseases of which almost half is accounted for by atherosclerotic cardiovascular disease (CVD) alone.

India is currently in the midst of this global CVD epidemic.

Atherosclerosis starts in early childhood and advances over several decades.

The atherosclerotic disease becomes symptomatic only when there is hemodynamically significant

\section{Corresponding author:}

\section{Dr. Aditya Jain 1}

E-mail: dradityajain94@gmail.com

Mobile number: +919806838520 narrowing of the vessels or when sudden thrombus formation occurs over a ruptured plaque. The slow, insidious progression of atherosclerosis allows an opportunity to detect the disease during its subclinical stage and to halt its progression through appropriate remedial measures.

Carotid artery intimal thickening is a marker of early atherosclerosis that can be assessed non invasively.

Changes in arterial wall thickness indicate structural arterial changes resulting from arterial remodeling, most often due to the atherosclerotic process. Carotid ultrasound for the measurement of carotid intima-media thickness (cIMT) and plaque assessment is one of the commonly used modalities for subclinical atherosclerosis assessment. cIMT is a well-validated research tool that has been translated into clinical practice ${ }^{[1,2]}$. On the other hand, cIMT is related to coronary risk factors such 
as age, smoking, hypertension, and LDL cholesterol. In several recent studies, cholesterol lowering medications led to a decrease in cIMT. These studies suggest that IMT is of high value as a marker of atherosclerosis ${ }^{[3]}$.

\section{Materials and Method}

Setting: Study was conducted in smokers both hypertensive and non-hypertensive in out-patients and in-patients in the Department of Medicine, G.R. Medical College, Gwalior (M.P.).

Design of study: The study was a case-control analytical study.

Period of study: January 2018 to August 2019

Ethical committee approval: Approval from the hospital ethical committee was obtained.

Consent: Informed consent was obtained from the subjects studied.

Inclusion Criteria: Cases are defined as smokers with hypertension above 18 years or equal. The subjects were poorly controlled hypertensive patients who defaulted or not compliant with medications. Controls were age and sex-matched individuals who are smokers and non-hypertensive.

Exclusion Criteria: All patients below 18 years and who failed to give consent.All patients who have associated respiratory illness like Chronic obstructive pulmonary disease, asthma, pulmonary tuberculosis, etc. All patients who are known cases of diabetics, dyslipidemia, coronary artery disease, stroke, valvular heart disease, and cardiomyopathies.

Statistical analysis: The data were managed on Microsoft excel spreadsheet (version 2007, Microsoft Corp., Seattle, Washington) and analyzed using SPSS for Windows (release 15.0, SPSS Inc., Chicago, IL, USA). Standard descriptive analysis was performed to analyze the baseline characteristics of the study population. Student's independent samples $t$-test was used for dichotomous risk factors and Pearson's correlation coefficient for continuous variables. Spearman's rank correlation was used for assessing the statistical significance of the cIMT trend across the age-groups. Multiple regression analysis was used for determining the relative strength of association between various CVD risk factors and CIMT. A $P$ value $<0.05$ was considered statistically significant for all the analyses performed. All the data were analyzed using IBM SPSS Ver. 20 software. Data were expressed as percentages and mean $\pm \mathrm{SD}$. The data was analyzed with "the independent samples t-test." This was significant if the $\mathrm{p}$-value is $<0.05$.

Assessment of carotid artery intima media thickness:Ultrasonographic scanning of the carotid arteries was performed using WIPRO - Ge logic 400 MD scanner with a linear transducer (mid frequency range $7.5-10 \mathrm{MHz}$ ). cIMT value of more than $0.8 \mathrm{~mm}$ is suggestive of significant atherosclerosis.

Measurement of blood pressure: Blood pressure was measured with a standard mercury sphygmomanometer after the subject had been seated for at least $5 \mathrm{~min}$. Hypertension was classified using JNC 8 guidelines measured at least two consecutive measurements. Latest recommendations as per the American College of Cardiology (ACC)/American Heart Association (AHA) for the accurate measurement of Blood Pressure were followed.

\section{Echocardiography:}

Two-dimensional, pulsed Doppler, M-mode and color flow Doppler echocardiographic studies were performed by an experienced cardiologist using a available "GE HEALTHCARE VIVIDS5" machine, with multifrequency linear probe.

\section{Results}

The data for this study was collected from 100 inpatients and out-patients who met the inclusion criteria. The results were organized as follows:- 


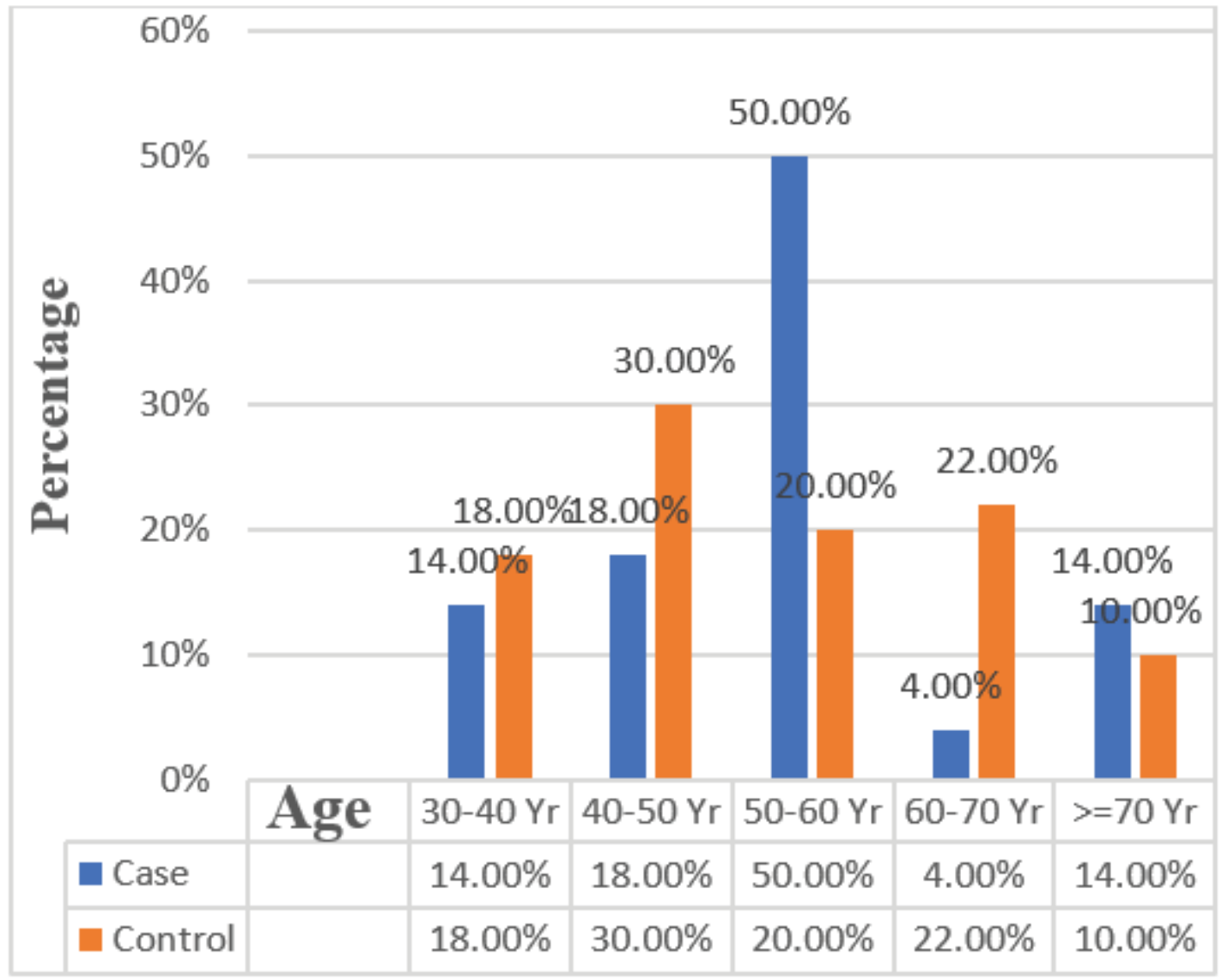

Graph 1: Age wise Distribution of Patients

The above table shows the association between the Patient group and Age group of the patient which was nonsignificant $(\mathrm{P}<0.05)$.

Table 1 : Sex distribution of cases and controls

\begin{tabular}{|c|c|c|c|}
\hline \multirow{2}{*}{ Sex } & \multicolumn{2}{|c|}{ GROUP } & \multirow{2}{*}{ Total } \\
\cline { 2 - 4 } & Case & Control & 40 \\
\cline { 2 - 4 } Female & 20 & 20 & \\
\hline Male & 30 & 30 & 60 \\
\hline Total & 50 & 50 & 100 \\
\hline
\end{tabular}

Both the cases and controls have an equal number of males and females in our study. 


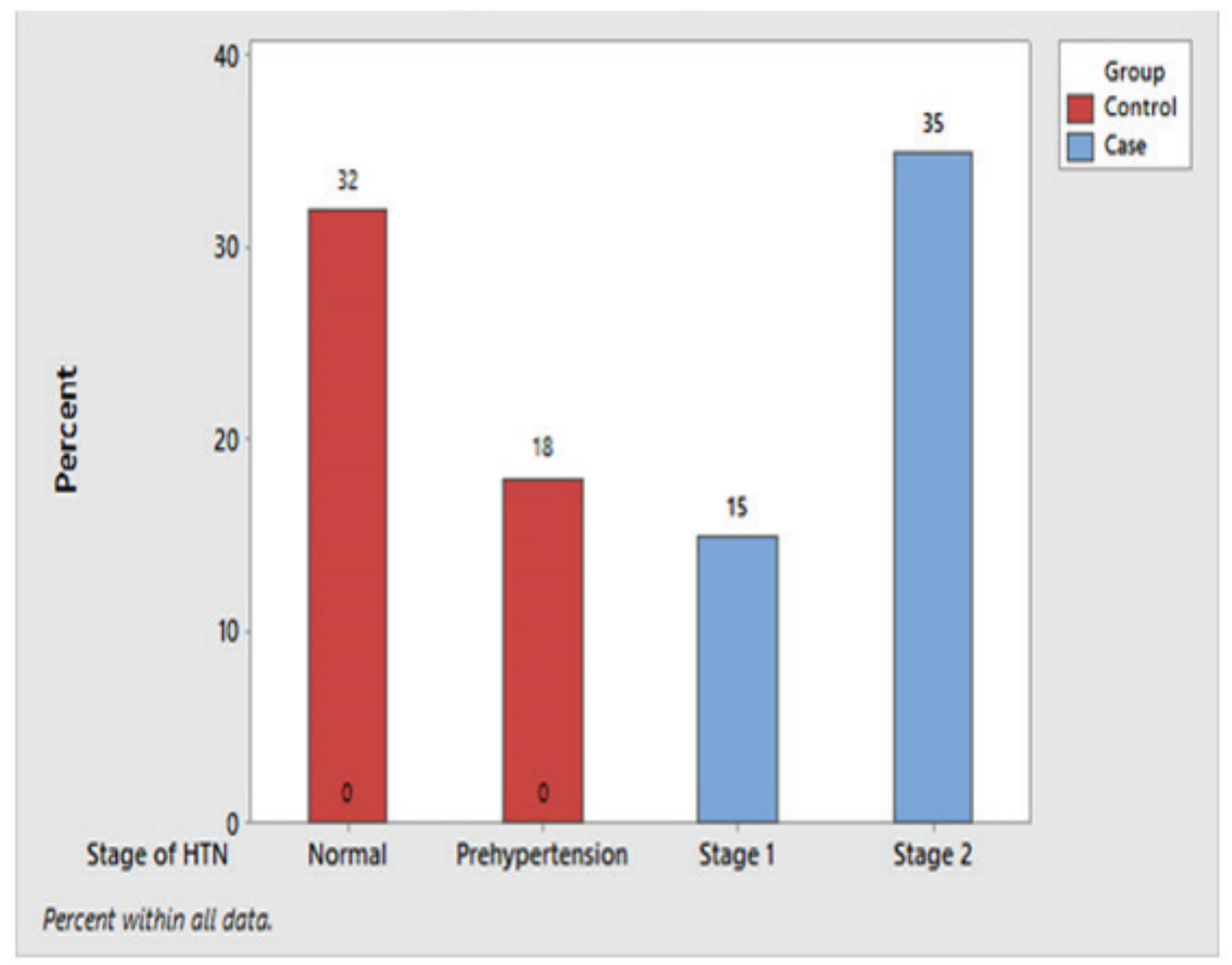

Graph 2 : Percentage Distribution of patients in different stages of hypertension

Table 2 : Comparison of mean value of cIMT in different groups

\begin{tabular}{|l|l|l|l|l|l|}
\hline \multirow{2}{*}{ cIMT(mm) } & Group & $\mathrm{N}$ & Mean & T Test & P value \\
\hline \multirow{2}{*}{ CIMT } & Case & 50 & $0.970 \mathrm{~mm}$ & 6.035 & \multirow{2}{*}{$0.000^{*}$} \\
\cline { 2 - 6 } & Control & 50 & $0.735 \mathrm{~mm}$ & \multirow{2}{*}{5.100} & \multirow{2}{*}{$0.000^{*}$} \\
\hline \multirow{2}{*}{ Left cIMT } & Case & 50 & $0.943 \mathrm{~mm}$ & & \\
\cline { 2 - 6 } & Control & 50 & $0.723 \mathrm{~mm}$ & \multirow{2}{*}{5.724} & \\
\hline
\end{tabular}

The difference in mean value of cIMT was found to be significant $(\mathrm{P}<0.05)$ as the mean of the Case group $(0.970 \mathrm{~mm})$ is significantly higher than that of the Control group $(0.735 \mathrm{~mm})$. The difference in mean value of Right cIMT was found to be significant $(\mathrm{P}<0.05)$ as the mean of the Case group $(0.943)$ is significantly higher than that of the Control group $(0.723 \mathrm{~mm})$. 
Similarly, the difference in mean value of Left cIMT was found to be significant $(\mathrm{P}<0.05)$ as the mean of the Case group $(0.998 \mathrm{~mm})$ is significantly higher than that of the Control group $(0.746 \mathrm{~mm})$.

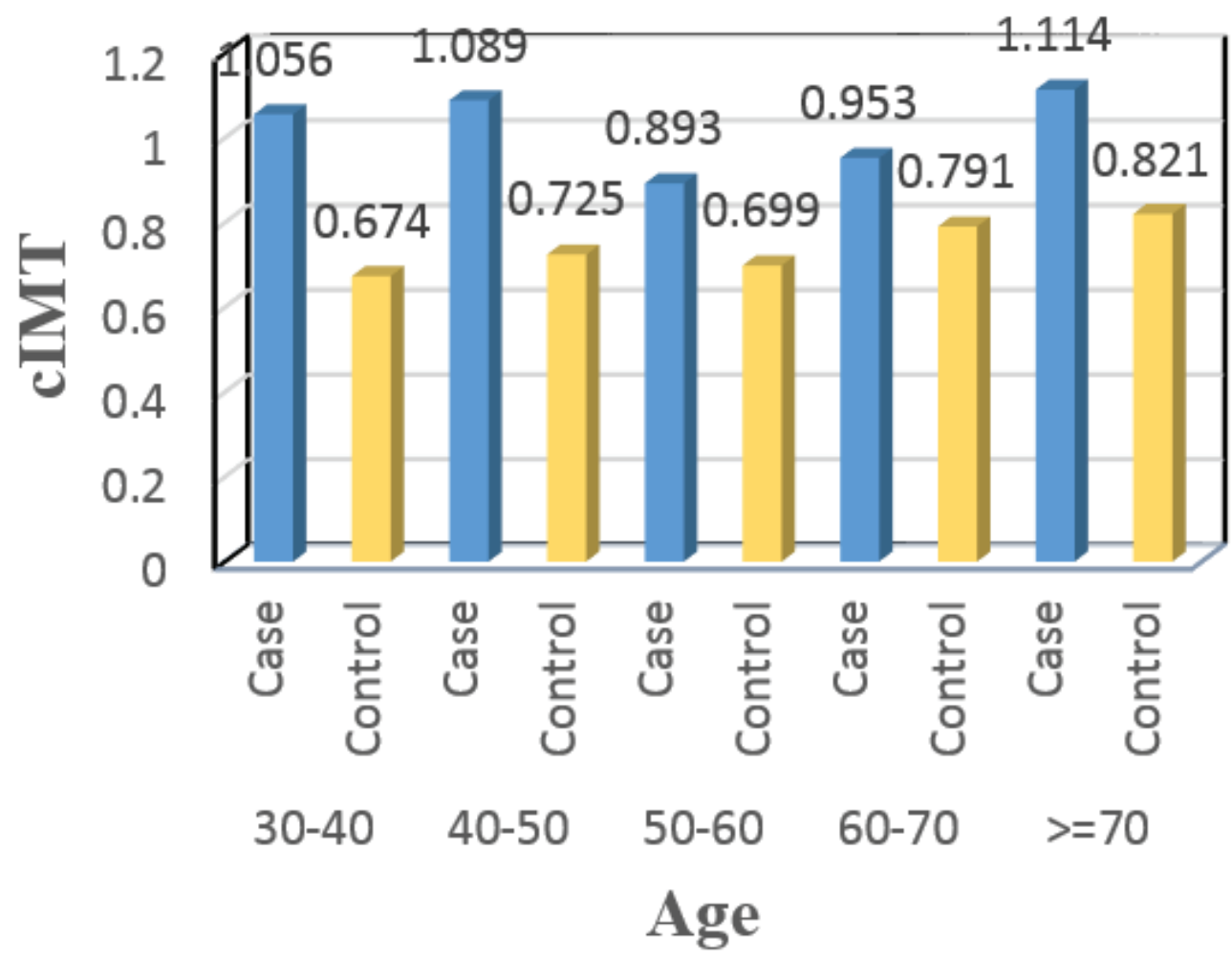

Graph 3 : Mean cIMT vs Age groups

Table 3 : Comparison of mean value of cIMT parameter of different groups

\begin{tabular}{|l|l|l|l|l|l|}
\hline \multirow{2}{*}{ Gender } & Group & N & Mean cIMT(mm) & T Test & P VALUE \\
\hline \multirow{2}{*}{ Female } & Case & 20 & .9725 & & \\
\cline { 2 - 6 } & Control & 20 & .7303 & 4.003 & $0.000^{*}$ \\
\hline \multirow{2}{*}{ Male } & Case & 30 & .9687 & & \\
\cline { 2 - 6 } & Control & 30 & .7375 & 4.456 & $0.000^{*}$ \\
\hline
\end{tabular}

The difference in mean values of cIMT for Females was found to be significant $(\mathrm{P}<0.05)$ for cases in comparison to controls. Similar results were seen in males. But cIMT values for males and females were statistically nonsignificant. 


\section{Discussion}

A total of 100 cases were included in this study from IPD as well as OPD.100 patients undergoing study were subjected to duplex scanning and color Doppler flow imaging followed by 2D echocardiography. All the cases and controls were investigated for lipid profile and other blood investigations.

In our study difference in mean value of Age was found to be non-significant $(\mathrm{P}>0.05)$, the mean age of the Case group (53.32) was higher than that of Control Group (52.06), but the difference is statistically nonsignificant.

Patients in the Case group had a higher percentage of $50 \%$ for $50-60$ years of age group while show the lowest percentage of $4 \%$ for $60-70$ years of age group. Similarly, in the Control group, patients show a higher percentage of $30 \%$ for $40-50$ years of age group while show the lowest percentage of $10 \%$ for above 70 years of age group.

This was a small study where only 100 patients were screened as compared to the other studies where the sample size was more as in The British Regional Heart Study by Shah Ebrahim et al ${ }^{[4]}$.

The difference in mean cIMT values of most of the Age groups was found to be significant $(\mathrm{P}<0.05)$ as mean cIMT for the Case group $(1.114 \mathrm{~mm})$ is significantly higher than that of the Control group $(0.821 \mathrm{~mm})$. This association is in concordance with Studies done by $\mathrm{J}$ Ahmad et $\mathrm{al}^{[5]}$, Hamma $\mathrm{S}$ et $\mathrm{al}^{[6]}$, Ratnakar Sahoo et $\mathrm{al}^{[7]}$ which also showed that CIMT increases with age. Henceforth, increasing age was statistically significant and comparable with previous studies.

There were 60 Males and 40 Females in our study. cIMT values were significantly higher in both females and males case group as compared to controls. Although in our study mean cIMT was significantly more in males as compared to females but the value is statistically not significant. In our study, gender was not found to be an independent risk factor for cIMT in contrast to previous studies done by Łoboz-Rudnicka $\mathrm{M}$ et $\mathrm{al}^{[8]}$ and Mohamed $\mathrm{M}$ et $\mathrm{al}^{[9]}$

The difference in the mean value of cIMT was found to be significant $(\mathrm{P}<0.05)$ for the Case group $(0.970 \mathrm{~mm})$, which is significantly higher than that of the Control group $(0.735 \mathrm{~mm})$. The maximum mean cIMT $(1.114 \mathrm{~mm})$ was for the Study population of above 70 years of age group. The difference in mean value of Right cIMT was found to be significant $(\mathrm{P}<0.05)$ as the mean of the Case group $(0.943 \mathrm{~mm})$ is significantly higher than that of the Control group $(0.723 \mathrm{~mm})$. Similarly, the difference in mean value of Left cIMT was found to be significant $(\mathrm{P}<0.05)$ as the mean of the Case group $(0.998 \mathrm{~mm})$ is significantly higher than that of the Control group $(0.746 \mathrm{~mm})$. As compared with the previous studies our findings were similar i.e. cIMT was significantly more in the study group which signifies that hypertensives are more prone to increased atherogenesis and subsequently increased cIMT. This result was comparable with the other previous study done by Costan G. Magnussen ${ }^{[10]}$ Although major limitation in our study was that effect of other risk factors such as smoking, diabetes could not be studied.

\section{Conclusion}

The present study and its observations makes it imminent that Hypertension affects every cIMT measurement of the study subjects. The association between increased cIMT and the hypertensive state persisted after accounting for the known predictors of carotid IMT, i.e., sex, age, smoking. cIMT measurement has a positive correlation with the increasing age. cIMT can be considered as a reliable marker for early atherosclerosis.

\section{Source of Funding- Self}

\section{Conflict of Interest- Nil}

Ethical Clearance- Taken from INSTITUITIONAL ETHICAL COMMITTEE,GAJRA RAJA MEDICAL COLLEGE,GWALIOR

\section{References}

[1] Stein JH, Fraizer MC, Aeschlimann SE, NelsonWorel J, McBride PE, Douglas PS. Vascular age: integrating carotid intima-media thickness measurements with global coronary risk assessment. Clin Cardiol 2004;27:388-392.

[2] Gepner AD, Keevil JG, Wyman RA, Korcarz CE, Aeschlimann SE, Busse KL, Stein JH. Use of carotid intima-media thickness and vascular age to 
modify cardiovascular risk prediction. J Am Soc Echocardiogr 2006;19:1170-1174

[3] Touboul PJ, Hennericim G, Meairs S. Mannheirn intima- media thickness consensus.Cerebrovasc Dis 2004; 18(4): 346-7.

[4] Ebrahim S, Papacosta O, Whincup P, Wannamethee G, Walker M, Nicolaides AN, Dhanjil S, Griffin M, Belcaro G, Rumley A, Lowe GD. Carotid plaque, intima media thickness, cardiovascular risk factors, and prevalent cardiovascular disease in men and women: the British Regional Heart Study. Stroke. 1999 Apr;30(4):841-50.

[5] J Ahmad et al. Inflammatory Markers, Insulin Resistance and Carotid Intima-MediaThickness in North-Indian Type 2 Diabetic Subjects. Japi • vol. 55 October 2007

[6] Hamma S et al, (Stroke 2001 April; 32(4): 830-5.

[7] Sahoo, Ratnakar \& Krishna, M \& Subrahmaniyan, D \& Dutta, Tarun \& Elangovan, S. (2009). Common carotid intima-media thickness in acute ischemic stroke: A case-control study. Neurology India. 57.
627-30. 10.4103/0028-3886.57822.

[8] Łoboz-Rudnicka M, Jaroch J, Bociąga Z, Rzyczkowska B, Uchmanowicz I, Polański J, Dudek K, Szuba A, Łoboz-Grudzień K. Impact of cardiovascular risk factors on carotid intima-media thickness: sex differences. Clin Interv Aging. 2016 May 23;11:721-31. doi: 10.2147/CIA.S103521. eCollection 2016.

[9] Mohamed M. Elrakhawy, Azza A. El-Baiomy, and Mervat M. El-Eshmawy Carotid Intima Media Thickness Is Independently Associated with Male Gender, Middle Age, and IGF-1 in Metabolically Healthy Obese Individuals Volume 2014 Article ID 5458047 pages| https://doi. org/10.1155/2014/545804.

[10] Magnussen CG. Carotid artery intima-media thickness and hypertensive heart disease: a short review. Clin Hypertens. 2017;23:7. Published 2017 Apr 2. doi:10.1186/s40885-017-0063-3 